\title{
Multiplicative decomposition and index number theory: an empirical application of the Sato-Vartia decomposition
}

\author{
Paul de Boer* \\ Econometric Institute Report EI 2007-16
}

\begin{abstract}
In De Boer (2006) the additive decomposition of the aggregate change in a variable into its factors was considered. I proposed to use the "ideal" Montgomery decomposition, developed in index number theory, rather than the commonly used methods in structural decomposition analysis and applied it to the example analyzed by Dietzenbacher and Los (1998) (D\&L). In this paper I consider the multiplicative decomposition and argue that from a theoretical point of view the "ideal" Sato-Vartia decomposition is to be preferred to the geometric average of the polar decompositions and that from a computational point of view it is to be preferred to the geometric average of all elementary decompositions. Application to the example of D\&L reveals that the three methods yield results that are very close to each other.
\end{abstract}

Keywords: multiplicative decomposition, index number theory, structural decomposition analysis.

*The author is indebted to Bert Balk for his suggestion to apply the Sato-Vartia indices to structural decomposition analysis and to Bart Los for putting the data sets at his disposal. 


\section{Introduction}

In a previous paper, De Boer (2006), I considered the additive decomposition of the aggregate change in a variable $\mathrm{V}, \mathrm{V}(1)-\mathrm{V}(0)$, the comparison period being denoted by 1 and the base period by 0 .

In the framework of structural decomposition analysis (SDA), Dietzenbacher and Los (1998),(D\&L), proved, that in case of $n$ factors the number of possible elementary additive decompositions, which from a theoretical point of view are equivalent, is equal to $n$ ! There are (n!)/2 "mirror pairs" (base and comparison period reversed, see De Haan, 2001), among which the pair of the polar decompositions. Each of the decompositions is complete, in the sense that there is no residual term, and is zero value robust, i.e. zero values can be dealt with. But none of them satisfies the requirement of time reversal which states that if we reverse base period and comparison period the decomposition should yield the reverse result, i.e. $V(0)-V(1)=-[V(1)-V(0)]$. Arithmetic averages of the mirror pairs can be shown to satisfy time reversal. In their empirical application D\&L decomposed the additive change in sectoral labor costs $(V)$ into the effects of changes in labor costs per unit, technical changes, and changes in final demand mix and in final demand levels. In their example there are $4 !=24$ elementary decompositions. They considered the arithmetic average of the two polar decompositions and the arithmetic average of all 24 decompositions and found out that both averages were quite close to each other. The disadvantage of the arithmetic average of the two polar decompositions is that it does not obey the requirement of factor reversal: if we reverse two factors we do not get the same result. This means that the order of appearance of the factors in the decomposition matters. The arithmetic average of all elementary decompositions meets the requirement of factor reversal, but the computation of $n$ ! decompositions are needed. In index number theory a decomposition that obeys factor reversal is called "ideal". In the previous paper I proposed to use alternatively the "ideal" Montgomery decomposition. For the example of D\&L I showed that the results of the Montgomery decomposition were very close to those either obtained by means of the arithmetic average of the two polar decompositions or by the arithmetic average of all elementary decompositions.

In this paper I consider the multiplicative decomposition of the aggregate change in a variable $\mathrm{V}$, i.e. $\mathrm{DV}[1,0]=\mathrm{V}(1) / \mathrm{V}(0)$, in the framework of the $\mathrm{D} \& \mathrm{~L}$ example. In section 2 I link for the case of $n=2$ factors (price and quantity) SDA to index number theory. We have 2!=2 elementary decompositions: the "polar ones", none of them satisfying the requirement of time reversal which, in the multiplicative case, states that if we reverse base period and comparison period the decomposition should yield the reciprocal result; i.e. $\mathrm{DV}[1,0] \times \mathrm{DV}[0,1]=1$. The commonly used solution is to take the geometric average of the two polar decompositions which satisfies time reversal. We show that the geometric average of the two polar decompositions, in case $n=2$ the only elementary decompositions, is nothing but the product of the price and quantity index of Fisher. If we reverse the two factors we obtain the same result: the Fisher index is ideal. But there are also other indices that are ideal. For the problem at hand the Sato-Vartia index is particularly suited and I present it in section 2 as well. Section 3 is devoted to the case of more than two factors. I take as example the multiplicative decomposition of the example of D\&L and I give the formula for the elementary decompositions and of the Sato-Vartia decomposition. Section 4 contains the results of the Sato-Vartia decomposition and of the geometric average of the two polar decompositions and the geometric average of all decompositions. It turns out that they are remarkably close to each other. Section 5 , finally, contains our conclusions. 


\section{Structural decomposition analysis and ideal indices in case of two factors}

\subsection{Notation}

Let $\mathrm{p}_{\mathrm{i}}(1)$ and $\mathrm{p}_{\mathrm{i}}(0)$ denote the prices of commodity $\mathrm{i}(=1, \ldots, n)$ in comparison and base period, and let $\mathrm{q}_{\mathrm{i}}(1)$ and $\mathrm{q}_{\mathrm{i}}(0)$ be the corresponding quantities. Then,

$\mathrm{v}_{\mathrm{i}}(1)=\mathrm{p}_{\mathrm{i}}(1) \mathrm{q}_{\mathrm{i}}(1)$ and $\mathrm{v}_{\mathrm{i}}(0)=\mathrm{p}_{\mathrm{i}}(0) \mathrm{q}_{\mathrm{i}}(0)$

are the expenditure on commodity $\mathrm{i}(=1, \ldots, \mathrm{n})$ in comparison and base period, whereas

$$
V(1)=\sum_{i=1}^{n} v_{i}(1)=\sum_{i=1}^{n} p_{i}(1) q_{i}(1) \text { and } V(0)=\sum_{i=1}^{n} v_{i}(0)=\sum_{i=1}^{n} p_{i}(0) q_{i}(0)
$$

are total expenditure in comparison and in base period, and

$\mathrm{s}_{\mathrm{i}}(1)=\frac{\mathrm{v}_{\mathrm{i}}(1)}{\mathrm{V}(1)}$ and $\mathrm{s}_{\mathrm{i}}(0)=\frac{\mathrm{v}_{\mathrm{i}}(0)}{\mathrm{V}(0)}$

are the shares of commodity $\mathrm{i}(=1, \ldots, \mathrm{n})$ in comparison and base period.

Finally, we define the ratio of total expenditure in comparison and in base period:

$D V[1,0]=\frac{V(1)}{V(0)}=\frac{\sum_{i=1}^{n} p_{i}(1) q_{i}(1)}{\sum_{i=1}^{n} p_{i}(0) q_{i}(0)}$

\subsection{Structural decomposition analysis and the "ideal" indices of Fisher}

In the terminology of structural decomposition analysis we have to decompose (4) into its factors "price" and "quantity". One possible solution, the so-called first polar decomposition, is:

$$
\operatorname{DV}[1,0]=\frac{\sum_{i=1}^{n} p_{i}(1) q_{i}(1)}{\sum_{i=1}^{n} p_{i}(0) q_{i}(1)} \times \frac{\sum_{i=1}^{n} p_{i}(0) q_{i}(1)}{\sum_{i=1}^{n} p_{i}(0) q_{i}(0)}
$$

It is easily seen that if we reverse base and comparison period ( 0 to 1 and 1 to 0 ) that for the first polar decomposition (5) generally DV[1,0] $\times \mathrm{DV}[0,1] \neq 1$ holds true. In the terminology of index number theory, the first polar decomposition does not meet the requirement of time reversal:

$\mathrm{DV}[1,0] \times \mathrm{DV}[0,1]=1$ 
However, this is not the only possibility. By reversing the time periods in the weights $(0$ to 1 , and 1 to 0 ) we obtain the second polar decomposition:

$$
\operatorname{DV}[1,0]=\frac{\sum_{i=1}^{n} p_{i}(1) q_{i}(0)}{\sum_{i=1}^{n} p_{i}(0) q_{i}(0)} \times \frac{\sum_{i=1}^{n} p_{i}(1) q_{i}(1)}{\sum_{i=1}^{n} p_{i}(1) q_{i}(0)}
$$

As is easily seen, the second polar decomposition, (7), does not meet the requirement of time reversal (6), either. The solution that is commonly adopted in structural decomposition analysis is to take the geometric mean of the two polar decompositions:

$$
\left[\frac{\sum_{i=1}^{n} p_{i}(1) q_{i}(1)}{\sum_{i=1}^{n} p_{i}(0) q_{i}(1)} \times \frac{\sum_{i=1}^{n} p_{i}(0) q_{i}(1)}{\sum_{i=1}^{n} p_{i}(0) q_{i}(0)}\right]^{1 / 2} \times\left[\frac{\sum_{i=1}^{n} p_{i}(1) q_{i}(0)}{\sum_{i=1}^{n} p_{i}(0) q_{i}(0)} \times \frac{\sum_{i=1}^{n} p_{i}(1) q_{i}(1)}{\sum_{i=1}^{n} p_{i}(1) q_{i}(0)}\right]^{1 / 2}
$$

which can easily be shown to meet the requirement of time reversal.

In order to link the structural decomposition approach to the index number approach we rewrite (8) to:

$$
\left[\frac{\sum_{i=1}^{n} p_{i}(1) q_{i}(1)}{\sum_{i=1}^{n} p_{i}(0) q_{i}(1)} \times \frac{\sum_{i=1}^{n} p_{i}(1) q_{i}(0)}{\sum_{i=1}^{n} p_{i}(0) q_{i}(0)}\right]^{1 / 2} \times\left[\frac{\sum_{i=1}^{n} p_{i}(1) q_{i}(1)}{\sum_{i=1}^{n} p_{i}(1) q_{i}(0)} \times \frac{\sum_{i=1}^{n} p_{i}(0) q_{i}(1)}{\sum_{i=1}^{n} p_{i}(0) q_{i}(0)}\right]^{1 / 2}
$$

In index number theory (omitting the, commonly used, factor 100) the first term is the definition of the Fisher price index $\left(\mathrm{P}^{\mathrm{F}}\right)$, defined as the geometric mean of the price indices of Paasche $\left(\mathrm{P}^{\mathrm{P}}\right)$ and of Laspeyres $\left(\mathrm{P}^{\mathrm{L}}\right)$ :

$$
\mathrm{P}^{\mathrm{P}}=\frac{\sum_{\mathrm{i}=1}^{\mathrm{n}} \mathrm{p}_{\mathrm{i}}(1) \mathrm{q}_{\mathrm{i}}(1)}{\sum_{\mathrm{i}=1}^{\mathrm{n}} \mathrm{p}_{\mathrm{i}}(0) \mathrm{q}_{\mathrm{i}}(1)} \text { and } \mathrm{P}^{\mathrm{L}}=\frac{\sum_{\mathrm{i}=1}^{\mathrm{n}} \mathrm{p}_{\mathrm{i}}(1) \mathrm{q}_{\mathrm{i}}(0)}{\sum_{\mathrm{i}=1}^{\mathrm{n}} \mathrm{p}_{\mathrm{i}}(0) \mathrm{q}_{\mathrm{i}}(0)}
$$

The second term of (8) is the Fisher quantity index $\left(\mathrm{Q}^{\mathrm{F}}\right)$ defined as the geometric mean of the quantity indices of Paasche $\left(\mathrm{Q}^{\mathrm{P}}\right)$ and Laspeyres $\left(\mathrm{Q}^{\mathrm{L}}\right)$ :

$$
\mathrm{Q}^{\mathrm{P}}=\frac{\sum_{\mathrm{i}=1}^{\mathrm{n}} \mathrm{p}_{\mathrm{i}}(1) \mathrm{q}_{\mathrm{i}}(1)}{\sum_{\mathrm{i}=1}^{\mathrm{n}} \mathrm{p}_{\mathrm{i}}(1) \mathrm{q}_{\mathrm{i}}(0)} \text { and } \mathrm{Q}^{\mathrm{L}}=\frac{\sum_{\mathrm{i}=1}^{\mathrm{n}} \mathrm{p}_{\mathrm{i}}(0) \mathrm{q}_{\mathrm{i}}(1)}{\sum_{\mathrm{i}=1}^{\mathrm{n}} \mathrm{p}_{\mathrm{i}}(0) \mathrm{q}_{\mathrm{i}}(0)}
$$


Consequently, the geometric mean of the two polar decompositions yields:

$\mathrm{DV}[1,0]=\mathrm{P}^{\mathrm{F}} \times \mathrm{Q}^{\mathrm{F}}$

It can easily seen that if in the formula of the Fisher price index, i.e. the first term of (9), we reverse the factors ( $p$ to $q$ and $q$ to $p$ ) that we obtain the formula given in the second term, the Fisher quantity index. Indices that exhibit this property of factor reversal are called "ideal".

\subsection{Another ideal index: Sato-Vartia ${ }^{1}$}

Sato (1976) and, independently, Vartia $(1974,1976)$ have discovered another pair of ideal price and quantity indices. In the derivation use will be made of the logarithmic mean $^{2}$ that for two positive numbers $a$ and $b$ is defined as:

$\mathrm{L}(\mathrm{a}, \mathrm{b})=\frac{\mathrm{a}-\mathrm{b}}{\ln (\mathrm{a} / \mathrm{b})}$ and $\mathrm{L}(\mathrm{a}, \mathrm{a})=\mathrm{a}$

Balk (2003) supplies a simple derivation from the identity:

$\sum_{i=1}^{n}\left[\left(s_{i}(1)-s_{i}(0)\right]=0\right.$

that easily follows from the adding-up of shares to 1 (see (3)).

Consider the logarithmic mean of $s_{i}(1)$ and $s_{i}(0)$ :

$\mathrm{L}\left[\mathrm{s}_{\mathrm{i}}(1), \mathrm{s}_{\mathrm{i}}(0)\right]=\frac{\mathrm{s}_{\mathrm{i}}(1)-\mathrm{s}_{\mathrm{i}}(0)}{\ln \left[\mathrm{s}_{\mathrm{i}}(1) / \mathrm{s}_{\mathrm{i}}(0)\right]}$

Using (12), it follows from (11) that:

$\sum_{i=1}^{n} L\left[s_{i}(1), s_{i}(0)\right] \ln \left[s_{i}(1) / s_{i}(0)\right]=0$

Using (3) and (4), expression (14) can be rewritten to:

$\sum_{\mathrm{i}=1}^{\mathrm{n}} \mathrm{L}\left[\mathrm{s}_{\mathrm{i}}(1), \mathrm{s}_{\mathrm{i}}(0)\right]\left[\ln \left\{\mathrm{v}_{\mathrm{i}}(1) / \mathrm{v}_{\mathrm{i}}(0)\right\}-\ln \{\mathrm{DV}(1,0)\}\right]=0$

from which it follows that: 
$\ln \{\mathrm{DV}(1,0)\}=\frac{\sum_{\mathrm{i}=1}^{\mathrm{n}} \mathrm{L}\left[\mathrm{s}_{\mathrm{i}}(1), \mathrm{s}_{\mathrm{i}}(0)\right]\left[\ln \left\{\mathrm{v}_{\mathrm{i}}(1) / \mathrm{v}_{\mathrm{i}}(0)\right\}\right]}{\sum_{\mathrm{j}=1}^{\mathrm{n}} \mathrm{L}\left[\mathrm{s}_{\mathrm{j}}(1), \mathrm{s}_{\mathrm{j}}(0)\right]}$

where we changed the index of summation in the denominator from $\mathrm{i}$ to $\mathrm{j}$.

Using definition (1) we obtain:

$\ln \{\mathrm{DV}(1,0)\}=\frac{\sum_{\mathrm{i}=1}^{\mathrm{n}} \mathrm{L}\left[\mathrm{s}_{\mathrm{i}}(1), \mathrm{s}_{\mathrm{i}}(0)\right]\left[\ln \left\{\mathrm{p}_{\mathrm{i}}(1) / \mathrm{p}_{\mathrm{i}}(0)\right\}\right]}{\sum_{\mathrm{j}=1}^{\mathrm{n}} \mathrm{L}\left[\mathrm{s}_{\mathrm{j}}(1), \mathrm{s}_{\mathrm{j}}(0)\right]}+\frac{\sum_{\mathrm{i}=1}^{\mathrm{n}} \mathrm{L}\left[\mathrm{s}_{\mathrm{i}}(1), \mathrm{s}_{\mathrm{i}}(0)\right]\left[\ln \left\{\mathrm{q}_{\mathrm{i}}(1) / \mathrm{q}_{\mathrm{i}}(0)\right\}\right]}{\sum_{\mathrm{j}=1}^{\mathrm{n}} \mathrm{L}\left[\mathrm{s}_{\mathrm{j}}(1), \mathrm{s}_{\mathrm{j}}(0)\right]}$

Taking the exponent, it follows from (15) that the Sato-Vartia decomposition reads:

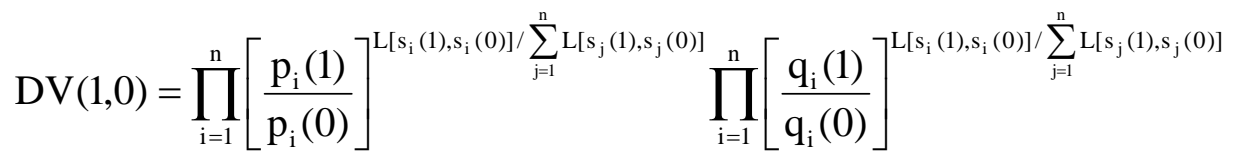

The first term in (16) is the definition of the price index of Sato-Vartia $\left(\mathrm{P}^{\mathrm{SV}}\right)$ and the second one the quantity index of Sato-Vartia $\left(Q^{S V}\right)$, so that (16) can, alternatively, be written as:

$\mathrm{DV}[1,0]=\mathrm{P}^{\mathrm{SV}} \times \mathrm{Q}^{\mathrm{SV}}$

As is seen from (13), the logarithmic mean is symmetric in $\mathrm{s}_{\mathrm{i}}(1)$ and $\mathrm{s}_{\mathrm{i}}(0)$, i.e.

$\mathrm{L}\left[\mathrm{s}_{\mathrm{i}}(1), \mathrm{s}_{\mathrm{i}}(0)\right]=\mathrm{L}\left[\mathrm{s}_{\mathrm{i}}(0), \mathrm{s}_{\mathrm{i}}(1)\right]$. Consequently, it easily follows from (16) that the SatoVartia decomposition satisfies time reversal. Because the exponents are the same, it is easily seen as well, that (16) satisfies factor reversal, so that the index numbers are ideal. Finally, Ang et al. (1998) proved that in an empirical application zeros can be replaced by epsilon small positive numbers. Consequently, the Sato-Vartia decomposition satisfies the requirement of zero-robustness as well.

\section{The case of many factors: the example of Dietzenbacher and Los (D\&L)}

\subsection{The D\&L model}

In their application D\&L used the input-output tables at basic prices for the Netherlands of 1986 and 1992. Defining the following vectors and matrices:

w: $\quad$ the $214 \times 1$ vector of sectoral labor costs;

u: $\quad$ the $214 \times 1$ vector of sectoral labor costs per unit of this sector's output (in money terms);

û : $\quad$ the $214 \times 214$ diagonal matrix with $u$ on the main diagonal; 
q: $\quad$ the $214 \times 1$ vector of sectoral outputs;

A: $\quad$ the $214 \times 214$ matrix of technical coefficients $a_{i j}$, measuring the input from sector $i$ in sector j, per unit of sector j's output;

$\mathrm{B}$ : the $214 \times 5$ matrix of bridge coefficients $b_{j k}$, measuring the fraction of the final demand in category $\mathrm{k}$ that is spent on products from sector $\mathrm{i}$, describing the final demand mix;

$\mathrm{f}$ : the $5 \times 1$ vector with total final demands ${ }^{3}$ in each of the five categories, i.e. private consumption, government consumption, exports, investments, and other items (imputed bank services, VAT, trade and transport margins),

they consider the model:

$\mathrm{w}=\hat{\mathrm{u} q}$

$\mathrm{q}=\mathrm{Aq}+\mathrm{Bf}$

of which the solution is:

$\mathrm{w}=\hat{\mathrm{u} L B f}$

where: $\mathrm{L}=(\mathrm{I}-\mathrm{A})^{-1}$ is the Leontief inverse.

In sum notation (18) reads:

$\mathrm{w}_{\mathrm{i}}=\mathrm{u}_{\mathrm{i}} \sum_{\mathrm{j}=1}^{\mathrm{n}} \sum_{\mathrm{k}=1}^{\mathrm{m}} \mathrm{l}_{\mathrm{ij}} \mathrm{b}_{\mathrm{jk}} \mathrm{f}_{\mathrm{k}} \quad \mathrm{i}=1, \ldots, \mathrm{n}$

where $\mathrm{w}_{\mathrm{i}}, \mathrm{u}_{\mathrm{i}}$ and $\mathrm{f}_{\mathrm{k}}$ are the typical elements of the vectors $\mathrm{w}, \mathrm{u}$ and $\mathrm{f}$, respectively; and $\mathrm{l}_{\mathrm{ij}}$ and $\mathrm{b}_{\mathrm{jk}}$ the typical elements of the matrices $L$ and $B$, respectively, whereas $n=214$ and $m=5$.

\subsection{Elementary decompositions}

The change in labor cost of sector $i$ is defined to be (see (19)):

$D W_{i}=\frac{w_{i}(1)}{w_{i}(0)}=D U_{i} \times \frac{\sum_{j=1}^{n} \sum_{k=1}^{m} l_{i j}(1) b_{j k}(1) f_{k}(1)}{\sum_{j=1}^{n} \sum_{k=1}^{m} l_{i j}(0) b_{j k}(0) f_{k}(0)}$,

where $\mathrm{DU}_{\mathrm{i}}=\frac{\mathrm{u}_{\mathrm{i}}(1)}{\mathrm{u}_{\mathrm{i}}(0)}$ is the change in the labor cost per unit . 
We want to decompose the second term at the right hand side of (20) into technical changes, $\frac{\mathrm{l}_{\mathrm{ij}}(1)}{\mathrm{l}_{\mathrm{ij}}(0)}$; changes in the final demand mix, $\frac{\mathrm{b}_{\mathrm{jk}}(1)}{\mathrm{b}_{\mathrm{jk}}(0)}$, and changes in the final demand levels, $\frac{f_{k}(1)}{f_{k}(0)}$.

A possible solution is the first polar decomposition. In order to alleviate the notation, we define:

(i) the effects in technical changes:

$\mathrm{DL}_{\mathrm{i} 1}=\frac{\sum_{\mathrm{j}=1}^{\mathrm{n}} \sum_{\mathrm{k}=1}^{\mathrm{m}} \mathrm{l}_{\mathrm{ij}}(1) \times \mathrm{b}_{\mathrm{jk}}(1) \times \mathrm{f}_{\mathrm{k}}(1)}{\sum_{\mathrm{j}=1}^{\mathrm{n}} \sum_{\mathrm{k}=1}^{\mathrm{m}} \mathrm{l}_{\mathrm{ij}}(0) \times \mathrm{b}_{\mathrm{jk}}(1) \times \mathrm{f}_{\mathrm{k}}(1)}$

(ii) the effects of changes in the final demand mix:

$\mathrm{DB}_{\mathrm{i} 1}=\frac{\sum_{\mathrm{j}=1}^{\mathrm{n}} \sum_{\mathrm{k}=1}^{\mathrm{m}} \mathrm{l}_{\mathrm{ij}}(0) \times \mathrm{b}_{\mathrm{jk}}(1) \times \mathrm{f}_{\mathrm{k}}(1)}{\sum_{\mathrm{j}=1}^{\mathrm{n}} \sum_{\mathrm{k}=1}^{\mathrm{m}} \mathrm{l}_{\mathrm{ij}}(0) \times \mathrm{b}_{\mathrm{jk}}(0) \times \mathrm{f}_{\mathrm{k}}(1)}$

(iii) the effects of the changes in the final demand levels:

$\mathrm{DF}_{\mathrm{i} 1}=\frac{\sum_{\mathrm{j}=1}^{\mathrm{n}} \sum_{\mathrm{k}=1}^{\mathrm{m}} \mathrm{l}_{\mathrm{ij}}(0) \times \mathrm{b}_{\mathrm{jk}}(0) \times \mathrm{f}_{\mathrm{k}}(1)}{\sum_{\mathrm{j}=1}^{\mathrm{n}} \sum_{\mathrm{k}=1}^{\mathrm{m}} \mathrm{l}_{\mathrm{ij}}(0) \times \mathrm{b}_{\mathrm{jk}}(0) \times \mathrm{f}_{\mathrm{k}}(0)}$

Then, we have the multiplicative decomposition:

$\mathrm{DW}_{\mathrm{i}}=\mathrm{DU}_{\mathrm{i}} \times \mathrm{DL}_{\mathrm{i} 1} \times \mathrm{DB}_{\mathrm{i} 1} \times \mathrm{DF}_{\mathrm{i} 1}$

However, this is only one of the $3 !=6$ elementary decompositions that are distinguished by Dietzenbacher and Los (1998).

By inverting the time periods in the weights (0 to 1 and 1 to 0 ) we obtain the second polar decomposition that we denote by the subscript 6 (we give in the appendix the four other elementary decompositions that, in our software, are denoted by the subscripts $2, \ldots, 5)$ : 


$$
\begin{aligned}
& \mathrm{DL}_{\mathrm{i} 6}=\frac{\sum_{\mathrm{j}=1}^{\mathrm{n}} \sum_{\mathrm{k}=1}^{\mathrm{m}} \mathrm{l}_{\mathrm{ij}}(1) \times \mathrm{b}_{\mathrm{jk}}(0) \times \mathrm{f}_{\mathrm{k}}(0)}{\sum_{\mathrm{j}=1}^{\mathrm{n}} \sum_{\mathrm{k}=1}^{\mathrm{m}} \mathrm{l}_{\mathrm{ij}}(0) \times \mathrm{b}_{\mathrm{jk}}(0) \times \mathrm{f}_{\mathrm{k}}(0)} \\
& \mathrm{DB}_{\mathrm{i} 6}=\frac{\sum_{\mathrm{j}=1}^{\mathrm{n}} \sum_{\mathrm{k}=1}^{\mathrm{m}} \mathrm{l}_{\mathrm{ij}}(1) \times \mathrm{b}_{\mathrm{jk}}(1) \times \mathrm{f}_{\mathrm{k}}(0)}{\sum_{\mathrm{j}=1}^{\mathrm{m}} \sum_{\mathrm{k}=1}^{m} \mathrm{l}_{\mathrm{ij}}(1) \times \mathrm{b}_{\mathrm{jk}}(0) \times \mathrm{f}_{\mathrm{k}}(0)} \\
& \mathrm{DF}_{\mathrm{i} 6}=\frac{\sum_{\mathrm{j}=1}^{\mathrm{n}} \sum_{\mathrm{k}=1}^{\mathrm{m}} \mathrm{l}_{\mathrm{ij}}(1) \times \mathrm{b}_{\mathrm{jk}}(1) \times \mathrm{f}_{\mathrm{k}}(1)}{\sum_{\mathrm{j}=1}^{\mathrm{n}} \sum_{\mathrm{k}=1}^{m} \mathrm{l}_{\mathrm{ij}}(1) \times \mathrm{b}_{\mathrm{jk}}(1) \times \mathrm{f}_{\mathrm{k}}(0)}
\end{aligned}
$$

Then, we have the multiplicative decomposition:

$$
\mathrm{DW}_{\mathrm{i}}=\mathrm{DU}_{\mathrm{i}} \times \mathrm{DL}_{\mathrm{i} 6} \times \mathrm{DB}_{\mathrm{i} 6} \times \mathrm{DF}_{\mathrm{i} 6}
$$

Neither (21), nor (22) satisfies the requirement of time reversal. As before the geometric mean:

$$
\mathrm{DW}_{\mathrm{i}}=\mathrm{DU}_{\mathrm{i}} \times\left(\mathrm{DL}_{\mathrm{i} 1} \times \mathrm{DL}_{\mathrm{i} 6}\right)^{1 / 2} \times\left(\mathrm{DB}_{\mathrm{i} 1} \times \mathrm{DB}_{\mathrm{i} 6}\right)^{1 / 2} \times\left(\mathrm{DF}_{\mathrm{i} 1} \times \mathrm{DF}_{\mathrm{i} 6}\right)^{1 / 2}
$$

satisfies time reversal, but it does not any longer satisfy factor reversal! The geometric mean of the two polar decompositions is not any longer "ideal" when the number of factors is larger than 2. This means that the order of appearance of the factors matters: if we would take for instance $b_{j k} f_{k} l_{i j}$ we will get another result for the geometric mean (23).

From the 6 elementary decompositions we can derive many combinations that satisfy time reversal, but only of them is "ideal": the geometric mean of all 6 elementary decompositions:

$$
\mathrm{DW}_{\mathrm{i}}=\mathrm{DU}_{\mathrm{i}} \times\left[\prod_{\mathrm{j}=1}^{6} \mathrm{DL}_{\mathrm{ij}}\right]^{1 / 6} \times\left[\prod_{\mathrm{j}=1}^{6} \mathrm{DB}_{\mathrm{ij}}\right]^{1 / 6} \times\left[\prod_{\mathrm{j}=1}^{6} \mathrm{DF}_{\mathrm{ij}}\right]^{1 / 6}
$$

but it requires the computation of six decompositions.

\subsection{Application of the Sato-Vartia decomposition to the D\&L model}

We define the shares: 
$\mathrm{s}_{\mathrm{ijk}}(1)=\frac{\mathrm{u}_{\mathrm{i}}(1) \mathrm{l}_{\mathrm{ij}}(1) \mathrm{b}_{\mathrm{jk}}(1) \mathrm{f}_{\mathrm{k}}(1)}{\mathrm{w}_{\mathrm{i}}(1)}$

and

$\mathrm{s}_{\mathrm{ijk}}(0)=\frac{\mathrm{u}_{\mathrm{i}}(0) \mathrm{l}_{\mathrm{ij}}(0) \mathrm{b}_{\mathrm{jk}}(0) \mathrm{f}_{\mathrm{k}}(0)}{\mathrm{w}_{\mathrm{i}}(0)}$

and the logarithmic mean:

$\mathrm{L}\left[\mathrm{s}_{\mathrm{ijk}}(1), \mathrm{s}_{\mathrm{ijk}}(1)\right]=\frac{\mathrm{s}_{\mathrm{ijk}}(1)-\mathrm{s}_{\mathrm{ijk}}(0)}{\ln \left[\mathrm{s}_{\mathrm{ijk}}(1) / \mathrm{s}_{\mathrm{ijk}}(0)\right]}$

Next, we define (compare expression (16)):

$\mathrm{DL}_{\mathrm{iSV}}=\prod_{\mathrm{j}=1}^{\mathrm{n}} \prod_{\mathrm{k}=1}^{\mathrm{m}}\left[\frac{\mathrm{l}_{\mathrm{ij}}(1)}{\mathrm{l}_{\mathrm{ij}}(0)}\right]^{\mathrm{L}\left[\mathrm{s}_{\mathrm{ijk}}(1), \mathrm{s}_{\mathrm{ijk}}(0)\right] / \sum_{\mathrm{j}=1}^{\mathrm{n}} \sum_{\mathrm{k}=1}^{\mathrm{m}} \mathrm{L}\left[\mathrm{s}_{\mathrm{ijk}}(1), \mathrm{s}_{\mathrm{ijk}}(0)\right]}$

$\mathrm{DB}_{\mathrm{iSV}}=\prod_{\mathrm{j}=1}^{\mathrm{n}} \prod_{\mathrm{k}=1}^{\mathrm{m}}\left[\frac{\mathrm{b}_{\mathrm{jk}}(1)}{\mathrm{b}_{\mathrm{jk}}(0)}\right]^{\mathrm{L}\left[\mathrm{s}_{\mathrm{ijk}}(1), \mathrm{s}_{\mathrm{ijk}}(0)\right] / \sum_{\mathrm{j}=1}^{\mathrm{n}} \sum_{\mathrm{k}=1}^{\mathrm{m}} \mathrm{L}\left[\mathrm{s}_{\mathrm{ijk}}(1), \mathrm{s}_{\mathrm{ijk}}(0)\right]}$

and

$\mathrm{DF}_{\mathrm{iSV}}=\prod_{\mathrm{j}=1}^{\mathrm{n}} \prod_{\mathrm{k}=1}^{\mathrm{m}}\left[\frac{\mathrm{f}_{\mathrm{k}}(1)}{\mathrm{f}_{\mathrm{k}}(0)}\right]^{\mathrm{L}\left[\mathrm{s}_{\mathrm{ijk}}(1), \mathrm{s}_{\mathrm{ijk}}(0)\right] / \sum_{\mathrm{j}=1}^{\mathrm{n}} \sum_{\mathrm{k}=1}^{\mathrm{m}} \mathrm{L}\left[\mathrm{s}_{\mathrm{ijk}}(1), \mathrm{s}_{\mathrm{ijk}}(0)\right]}$

Then, the Sato-Vartia decomposition of the ratio of sectoral labor cost of sector i reads:

$\mathrm{DW}_{\mathrm{i}}=\mathrm{DU}_{\mathrm{i}} \times \mathrm{DL}_{\mathrm{iSV}} \times \mathrm{DB}_{\mathrm{iSV}} \times \mathrm{DF}_{\mathrm{iSV}}$

This decomposition obviously satisfies time reversal, but also factor reversal, i.e. the Sato-Vartia decomposition is "ideal". It is clear that generalization of this decomposition to the case of more than three factors is straightforward.

To summarize this section, I prefer the use of the "ideal" Sato-Vartia approach that only requires one decomposition for any number of factors, rather than the use of the geometric mean of the two polar decompositions which is not ideal so that the order of appearance of the factors matters, or the use of the geometric mean of all decompositions that is "ideal", but requires the computation of an ever increasing number of decompositions when the number of factors increases. 


\section{Results}

In table 1 I give the results for nine sectors: four with a large percentage growth and five with large absolute growth (the results of the other sectors show the same pattern).

Table 1. Results

\begin{tabular}{|c|c|c|c|c|}
\hline Sector & $\begin{array}{c}\text { Geometric } \\
\text { mean of all } \\
\text { decompositions }\end{array}$ & $\begin{array}{c}\text { standard } \\
\text { deviation of all } \\
\text { decompositions } \\
\end{array}$ & $\begin{array}{c}\text { geometric mean } \\
\text { of polar } \\
\text { decompositions }\end{array}$ & $\begin{array}{c}\text { Sato-Vartia } \\
\text { decomposition }\end{array}$ \\
\hline \multicolumn{5}{|c|}{ Sectors with largest percentage growth } \\
\hline $\begin{array}{l}156 \text { economic } \\
\text { advising agents }\end{array}$ & $w(86)=539$ & $\mathrm{w}(92)=1436$ & $\mathrm{DW}=2.664$ & $\mathrm{DU}=1.015$ \\
\hline DL & 1.640 & 0.0817 & 1.640 & 1.641 \\
\hline $\mathrm{DB}$ & 1.265 & 0.0640 & 1.264 & 1.263 \\
\hline DF & 1.266 & 0.0017 & 1.266 & 1.266 \\
\hline $\begin{array}{l}153 \text { computer } \\
\text { services }\end{array}$ & $w(86)=1245$ & $\mathrm{w}(92)=2842$ & $\mathrm{DW}=2.283$ & $\mathrm{DU}=1.096$ \\
\hline DL & 1.416 & 0.0380 & 1.417 & 1.416 \\
\hline $\mathrm{DB}$ & 1.151 & 0.0310 & 1.150 & 1.151 \\
\hline DF & 1.278 & 0.0014 & 1.279 & 1.279 \\
\hline $\begin{array}{l}127 \text { beverage } \\
\text { serving services } \\
\text { (no lodging) }\end{array}$ & $w(86)=189$ & $w(92)=416$ & $\mathrm{DW}=2.201$ & $\mathrm{DU}=1.085$ \\
\hline DL & 1.084 & 0.0140 & 1.084 & 1.082 \\
\hline $\mathrm{DB}$ & 1.433 & 0.0179 & 1.433 & 1.436 \\
\hline $\mathrm{DF}$ & 1.306 & 0.0010 & 1.306 & 1.306 \\
\hline $\begin{array}{l}157 \text { other } \\
\text { business } \\
\text { services }\end{array}$ & $\mathrm{w}(86)=1032$ & $\mathrm{w}(92)=2249$ & $\mathrm{DW}=2.179$ & $\mathrm{DU}=1.005$ \\
\hline $\mathrm{DL}$ & 1.384 & 0.0460 & 1.385 & 1.391 \\
\hline DB & 1.237 & 0.0426 & 1.236 & 1.230 \\
\hline $\mathrm{DF}$ & 1.267 & 0.0035 & 1.267 & 1.267 \\
\hline \multicolumn{5}{|c|}{ Sectors with the largest absolute growth } \\
\hline $\begin{array}{l}121 \text { wholesale } \\
\text { trade }\end{array}$ & $w(86)=13212$ & $\mathrm{w}(92)=21712$ & $\mathrm{DW}=1.568$ & $\mathrm{DU}=1.144$ \\
\hline DL & 1.015 & 0.0006 & 1.015 & 1.015 \\
\hline $\mathrm{DB}$ & 1.032 & 0.0008 & 1.032 & 1.032 \\
\hline $\mathrm{DF}$ & 1.309 & 0.0007 & 1.309 & 1.309 \\
\hline 123 retail trade & $\mathrm{w}(86)=7726$ & $w(92)=12225$ & $\mathrm{DW}=1.582$ & $\mathrm{DU}=1.160$ \\
\hline DL & 0.999 & 0.0000 & 0.999 & 0.999 \\
\hline $\mathrm{DB}$ & 1.035 & 0.0000 & 1.035 & 1.035 \\
\hline $\mathrm{DF}$ & 1.320 & 0.0000 & 1.320 & 1.320 \\
\hline $\begin{array}{l}146 \text { railways, } \\
\text { communication } \\
\text { services, taxi } \\
\text { and coach } \\
\text { enterprises }\end{array}$ & $w(86)=5385$ & $w(92)=8232$ & $\mathrm{DW}=1.529$ & $\mathrm{DU}=1.049$ \\
\hline $\mathrm{DL}$ & 1.059 & 0.0036 & 1.059 & 1.059 \\
\hline $\mathrm{DB}$ & 1.064 & 0.0036 & 1.064 & 1.065 \\
\hline Df & 1.294 & 0.0006 & 1.294 & 1.294 \\
\hline
\end{tabular}




\begin{tabular}{|l|c|c|c|c|}
\hline $\begin{array}{l}\text { 171 special } \\
\text { (primary) } \\
\text { education (for } \\
\text { handicapped } \\
\text { children) }\end{array}$ & $\mathrm{w}(86)=8221$ & $\mathrm{w}(92)=10863$ & $\mathrm{DW}=1.321$ & $\mathrm{DU}=1.152$ \\
\hline DL & 0.999 & 0.0000 & 0.999 & 0.999 \\
\hline DB & 0.939 & 0.0000 & 0.939 & 0.939 \\
\hline DF & 1.223 & 0.0000 & 1.223 & 1.223 \\
\hline $\begin{array}{l}162 \text { local } \\
\text { government }\end{array}$ & $\mathrm{w}(86)=6933$ & $\mathrm{w}(92)=9417$ & $\mathrm{DW}=1.358$ & $\mathrm{DU}=1.097$ \\
\hline DL & 0.973 & 0.0013 & 0.973 & 0.973 \\
\hline DB & 1.030 & 0.0011 & 1.030 & 1.030 \\
\hline DF & 1.236 & 0.0007 & 1.236 & 1.236 \\
\hline
\end{tabular}

In the heading for each sector I give (omitting the index i):

w(86) : sectoral labor costs in 1986;

w(92) : sectoral labor costs in 1992;

$\mathrm{DW}=\frac{\mathrm{W}(92)}{\mathrm{W}(86)}$ : ratio of labor costs in 1992 and1986;

$\mathrm{DU}=\frac{\mathrm{u}(92)}{\mathrm{u}(86)} \quad$ : ratio of labor costs per unit of output (in money terms) in 1992 and1986,

which are the same for all decompositions.

In the second column I give the geometric average of all decompositions; in column three the standard deviation are presented from which it can be inferred that the elementary decompositions did not vary much. Therefore, the geometric mean of the two polar decompositions, given in column four is very close to the geometric average of all decompositions. Column five, finally, contains the results for the Sato-Vartia decomposition which are very close to the results obtained in columns two and four. I conclude that from an empirical point of view the three methods yield (almost) the same results.

\section{Concluding remarks}

In this paper I have tried to argue that from a theoretical point of view the use of the "ideal" Sato-Vartia approach that only requires one decomposition for any number of factors, is to be preferred to the use of the geometric mean of the two polar decompositions which is not ideal so that the order of appearance of the factors matters, and to the use of the geometric mean of all decompositions that is "ideal", but requires the computation of an ever increasing number of decompositions when the number of factors increases. In the example at hand it turned out that from an empirical point of view the three methods yielded almost the same results. 
${ }^{1}$ Siegel(1945) derives another ideal index. Both Balk (2003) and Ang et al. (2004) argue that its formula is relatively complex, see the appendix of Ang et al. in which they give the formula for $\mathrm{n}=4$. The Montgomery-Vartia index, the multiplicative variant of the Montgomery index that De Boer (2006) used for the additive decomposition does not meet the requirement that it is not linear homogeneous in prices (quantities), see Balk (2003).

${ }^{2}$ The properties (Balk, 2003) are: $\min (\mathrm{a}, \mathrm{b}) \leq \mathrm{L}(\mathrm{a}, \mathrm{b}) \leq \max (\mathrm{a}, \mathrm{b})$; $\mathrm{L}(\mathrm{a}, \mathrm{b})$ is continuous; $\mathrm{L}(\lambda \mathrm{a}, \lambda \mathrm{b})=\lambda \mathrm{L}(\mathrm{a}, \mathrm{b}) ; \mathrm{L}(\mathrm{a}, \mathrm{b})=\mathrm{L}(\mathrm{b}, \mathrm{a}) ;$ and $\sqrt{\mathrm{ab}} \leq \mathrm{L}(\mathrm{a}, \mathrm{b}) \leq \frac{\mathrm{a}+\mathrm{b}}{2}$. We give his footnote 1 :

"The logarithmic mean was introduced in the economics literature by Törnqvist in 1935 in an unpublished memo of the Bank of Finland; see Törnqvist et al.(1985) .....A proof of the fact that $(\mathrm{ab})^{1 / 2} \leq \mathrm{L}(\mathrm{a}, \mathrm{b}) \leq(\mathrm{a}+\mathrm{b}) / 2$ was provided by Lorenzen (1990)".

${ }^{3}$ In De Boer (2006) it is argued that a change in stocks is not an appropriate final demand category and he split a stock change over all other items of the row according to the pertinent shares in total output.

\section{References}

Ang, B.W., Liu, F.L. \& Chung, H.-S. (2004) A generalized Fisher index approach to energy decomposition analysis, Energy Economics, 26, pp.757-763.

Balk, B.M. (2003) Ideal indices and indicators for two or more factors, Journal of Economic and Social Measurement, 28, pp. 203-217.

De Boer, P.M.C. (2006) Structural decomposition analysis and index number theory: an empirical application of the Montgomery decomposition, Econometric Institute Report El 2006-39, Erasmus University Rotterdam, the Netherlands.

De Haan, M. (2001) A structural decomposition analysis of pollution in the Netherlands, Economic Systems Research, 13, pp. 181- 196.

Dietzenbacher, E. \& Los, B. (1998) Structural decomposition techniques: sense and sensitivity, Economic Systems Research, 10, pp. 307-323.

Lorenzen, G. (1990) Konsistent addierbare relative Änderungen, Allgemeines Statistisches Archiv, 74, pp. 336-344.

Sato, K. (1976) The ideal log-change index number, The Review of Economics and Statistics, 58, pp. 223-228.

Siegel, I.H. (1945) The generalized "ideal" index-number formula, Journal of the American Statistical Association, 40, pp. 520-523.

Törnqvist, L.,Vartia, P. \& Vartia, Y.O. (1985) How should relative changes be measured?, The American Statistician, 39, pp. 43-46.

Vartia, Y.O. (1974) Relative changes and index numbers, Licentiate Thesis, University of Helsinki, (The Research Institute of the Finnish Economy, Helsinki, 1976).

Vartia, Y.O. (1976) Ideal log-change index numbers, The Scandinavian Journal of Statistics, 3, pp. 121-126. 
Appendix The four non-polar elementary decompositions $(e=2, \ldots, 5)$

\begin{tabular}{|c|c|c|c|}
\hline $\mathrm{E}$ & $\mathrm{DL}_{\mathrm{ie}}$ & $\mathrm{DB}_{\mathrm{ie}}$ & $\mathrm{DF}_{\mathrm{ie}}$ \\
\hline 2 & $\frac{\sum_{\mathrm{j}=1}^{\mathrm{n}} \sum_{\mathrm{k}=1}^{\mathrm{m}} \mathrm{l}_{\mathrm{ij}}(1) \mathrm{b}_{\mathrm{jk}}(1) \mathrm{f}_{\mathrm{k}}(1)}{\sum_{\mathrm{j}=1}^{\mathrm{n}} \sum_{\mathrm{k}=1}^{\mathrm{m}} \mathrm{l}_{\mathrm{ij}}(0) \mathrm{b}_{\mathrm{jk}}(1) \mathrm{f}_{\mathrm{k}}(1)}$ & $\frac{\sum_{\mathrm{j}=1}^{\mathrm{n}} \sum_{\mathrm{k}=1}^{\mathrm{m}} \mathrm{l}_{\mathrm{ij}}(0) \mathrm{b}_{\mathrm{jk}}(1) \mathrm{f}_{\mathrm{k}}(0)}{\sum_{\mathrm{j}=1}^{\mathrm{n}} \sum_{\mathrm{k}=1}^{\mathrm{m}} \mathrm{l}_{\mathrm{ij}}(0) \mathrm{b}_{\mathrm{jk}}(0) \mathrm{f}_{\mathrm{k}}(0)}$ & $\frac{\sum_{\mathrm{j}=1}^{\mathrm{n}} \sum_{\mathrm{k}=1}^{\mathrm{m}} \mathrm{l}_{\mathrm{ij}}(0) \mathrm{b}_{\mathrm{jk}}(1) \mathrm{f}_{\mathrm{k}}(1)}{\sum_{\mathrm{j}=1}^{\mathrm{n}} \sum_{\mathrm{k}=1}^{\mathrm{m}} \mathrm{l}_{\mathrm{ij}}(0) \mathrm{b}_{\mathrm{jk}}(1) \mathrm{f}_{\mathrm{k}}(0)}$ \\
\hline 3 & $\frac{\sum_{\mathrm{j}=1}^{\mathrm{n}} \sum_{\mathrm{k}=1}^{\mathrm{m}} \mathrm{l}_{\mathrm{ij}}(1) \mathrm{b}_{\mathrm{jk}}(0) \mathrm{f}_{\mathrm{k}}(1)}{\sum_{\mathrm{j}=1}^{\mathrm{n}} \sum_{\mathrm{k}=1}^{\mathrm{m}} \mathrm{l}_{\mathrm{ij}}(0) \mathrm{b}_{\mathrm{jk}}(0) \mathrm{f}_{\mathrm{k}}(1)}$ & $\frac{\sum_{j=1}^{n} \sum_{k=1}^{m} l_{i j}(1) b_{j k}(1) f_{k}(1)}{\sum_{j=1}^{n} \sum_{k=1}^{m} l_{i j}(1) b_{j k}(0) f_{k}(1)}$ & $\frac{\sum_{\mathrm{j}=1}^{\mathrm{n}} \sum_{\mathrm{k}=1}^{\mathrm{m}} \mathrm{l}_{\mathrm{ij}}(0) \mathrm{b}_{\mathrm{jk}}(0) \mathrm{f}_{\mathrm{k}}(1)}{\sum_{\mathrm{j}=1}^{\mathrm{n}} \sum_{\mathrm{k}=1}^{\mathrm{m}} \mathrm{l}_{\mathrm{ij}}(0) \mathrm{b}_{\mathrm{jk}}(0) \mathrm{f}_{\mathrm{k}}(0)}$ \\
\hline 4 & $\frac{\sum_{\mathrm{j}=1}^{\mathrm{n}} \sum_{\mathrm{k}=1}^{\mathrm{m}} \mathrm{l}_{\mathrm{ij}}(1) \mathrm{b}_{\mathrm{jk}}(0) \mathrm{f}_{\mathrm{k}}(0)}{\sum_{\mathrm{j}=1}^{\mathrm{n}} \sum_{\mathrm{k}=1}^{\mathrm{m}} \mathrm{l}_{\mathrm{ij}}(0) \mathrm{b}_{\mathrm{jk}}(0) \mathrm{f}_{\mathrm{k}}(0)}$ & $\frac{\sum_{j=1}^{n} \sum_{k=1}^{m} l_{i j}(1) b_{j k}(1) f_{k}(1)}{\sum_{j=1}^{n} \sum_{k=1}^{m} l_{i j}(1) b_{j k}(0) f_{k}(1)}$ & $\frac{\sum_{\mathrm{j}=1}^{\mathrm{n}} \sum_{\mathrm{k}=1}^{\mathrm{m}} \mathrm{l}_{\mathrm{ij}}(1) \mathrm{b}_{\mathrm{jk}}(0) \mathrm{f}_{\mathrm{k}}(1)}{\sum_{\mathrm{i}=1}^{\mathrm{n}} \sum_{\mathrm{j}=1}^{\mathrm{m}} \mathrm{l}_{\mathrm{ij}}(1) \mathrm{b}_{\mathrm{jk}}(0) \mathrm{f}_{\mathrm{k}}(0)}$ \\
\hline 5 & $\frac{\sum_{\mathrm{j}=1}^{\mathrm{n}} \sum_{\mathrm{k}=1}^{\mathrm{m}} \mathrm{l}_{\mathrm{ij}}(1) \mathrm{b}_{\mathrm{jk}}(1) \mathrm{f}_{\mathrm{k}}(0)}{\sum_{\mathrm{j}=1}^{\mathrm{n}} \sum_{\mathrm{k}=1}^{\mathrm{m}} \mathrm{l}_{\mathrm{ij}}(0) \mathrm{b}_{\mathrm{jk}}(1) \mathrm{f}_{\mathrm{k}}(0)}$ & $\frac{\sum_{\mathrm{j}=1}^{\mathrm{n}} \sum_{\mathrm{k}=1}^{\mathrm{m}} \mathrm{l}_{\mathrm{ij}}(0) \mathrm{b}_{\mathrm{jk}}(1) \mathrm{f}_{\mathrm{k}}(0)}{\sum_{\mathrm{j}=1}^{\mathrm{n}} \sum_{\mathrm{k}=1}^{\mathrm{m}} \mathrm{l}_{\mathrm{ij}}(0) \mathrm{b}_{\mathrm{jk}}(0) \mathrm{f}_{\mathrm{k}}(0)}$ & $\frac{\sum_{\mathrm{j}=1}^{\mathrm{n}} \sum_{\mathrm{k}=1}^{\mathrm{m}} \mathrm{l}_{\mathrm{ij}}(1) \mathrm{b}_{\mathrm{jk}}(1) \mathrm{f}_{\mathrm{k}}(1)}{\sum_{\mathrm{j}=1}^{\mathrm{n}} \sum_{\mathrm{k}=1}^{\mathrm{m}} \mathrm{l}_{\mathrm{ij}}(1) \mathrm{b}_{\mathrm{jk}}(1) \mathrm{f}_{\mathrm{k}}(0)}$ \\
\hline
\end{tabular}

